\title{
EDUCAÇÃO AMBIENTAL E SUSTENTABILIDADE DOS RECURSOS HÍDRICOS NO COLÉGIO ESTADUAL GONÇALO ROLLEMBERG LEITE
}

\author{
Environmental education and sustainability of water resources in \\ ColégioEstadualGonçaloRollembergLeite
}
Educación ambiental y sostenibilidad de los recursos hídricos en laColégio Estadual GonçaloRollembergLeite

\author{
Simone Neves Cunha* \\ Marcia Eliane Silva Carvalho**
}

\begin{abstract}
*Mestranda em Ensino de Ciências Ambientais (UFS) - nevesimone@yahoo.com.br ** Professora do Mestrado em Ensino de Ciências Ambientais (UFS) - marciacarvalho_ufs@yahoo.com.br
\end{abstract}

Recebido em 19/10/2019. Aceito para publicação em 20/10/2019.

Versão online publicada em 10/11/2019 (http://seer.ufrgs.br/paraonde)

\begin{abstract}
Resumo:
A presente pesquisa-ação teve como objetivo promover ações de educação ambiental, com foco na água, junto à comunidade do Colégio Estadual Professor Gonçalo Rollemberg Leite em Aracaju-SE. Parte-se do pressuposto de que é necessário repensar as relações estabelecidas entre a sociedade e o meio ambiente e de que a escola é um espaço de extrema importância para a formação de sujeitos preocupados em se engajar na formação de uma sociedade sustentável. Neste sentido, buscou-se verificar a postura da comunidade escolar em sua relação com o meio ambiente e mais especificamente com relação a utilização da água; Sensibilizar os alunos quanto ao uso racional da água; Desenvolver uma ação interdisciplinar, integrando alunos e professores em prol da sustentabilidade dos recursos hídricos; Divulgar as ações junto à comunidade escolar como forma de envolver mais pessoas no processo de sensibilização para a sustentabilidade dos recursos hídricos. Para tanto foram realizadas: rodas de conversa; produção de cartazes; exibição de vídeos educativos; visita a exposição; atividade de campo no entorno e dentro do ambiente escolar; confecção de material pedagógico sugerido pelos alunos, que foi utilizado no dia da culminância. As ações desenvolvidas evidenciaram um maior compromisso dos envolvidos para com o meio ambiente e uma maior autonomia dos alunos na tomada de decisões e na busca de soluções para os problemas encontrados. Os mesmos demonstraram o interesse na criação de um clube de protagonismo em educação ambiental e no reuso das águas para a promoção da sustentabilidade dos recursos hidricos no ambiente escolar.
\end{abstract}

Palavras-chave: Educação ambiental. Sustentabilidade. Água.

\begin{abstract}
:
This action research aimed to promote environmental education actions, focusing on water, within the community of the ColégioEstadual Professor GonçaloRollembergLeite in AracajuSE. It is assumed that it is necessary to rethink the relationships established between society and the environment and that the school is an extremely important space for the formation of subjects concerned with engaging in the formation of a sustainable society. In this sense, we sought to verify the attitude of the school community in its relationship with the environment and more specifically with regard to water use; Sensitize students about the rational use of water; Develop an interdisciplinary action, integrating students and teachers for the sustainability of water resources; Disseminate the actions within the school community as a way to involve more people in the process of awareness for the sustainability of water resources. For this purposepurpose, were carried out: informal discussionsconversationwheels; production of posters; exhibition of educational videos; visit
\end{abstract}


to anhe exhibition; field workactivity in and around the school environment; preparation of pedagogical material suggested by the students, which wasere used on the culmination day. The actions developed showed a greater commitment towards environmental sustainability of those involved in the project,those involved to the environment and greater autonomy of students in decision-making and seeking solutions to the problems encountered. They showed interest in the creation of a dedicatedleading club toin environmental education and in the reuse of waters to promote the sustainability of water resources in the school environment.

Key-words:Environmental education. Sustainability. Water.

\section{Resumen:}

Esta investigación de acción tuvo como objetivo promover acciones de educación ambiental, centradas en el agua, con la comunidad del Colégio Estadual ProfessorGonçaloRollembergLeite ubicado en Aracaju-SE. Se asume que es necesario repensar las relaciones establecidas entre la sociedad y el medio ambiente y que la escuela es un espacio indispensable para la formación de sujetos interesados en intervenir en la constitución de una sociedad sostenible. Así que, buscamos verificar la actitud de la comunidad escolar en su relación con el medio ambiente y más concretamente con relación al uso del agua; Concienciar a los estudiantes acerca del uso racional del agua; Desarrollar una acción interdisciplinaria, integrando estudiantes y docentes en dirección a la sostenibilidad de los recursos hídricos; Difundir las acciones con la comunidad escolar como una forma de involucrar a más personas en el proceso de concientización para la sostenibilidad de los recursos hídricos. Para ello se efectuaron: ruedas de conversación; producción de carteles; exhibición de videos educativos; visita a la exposición; actividad de campo dentro del ambiente escolar y sus alrededores; desarrollo de material pedagógico propuesto por los alumnos, lo cual se utilizó en el día de la culminación. Las acciones desarrolladas demostraron un mayor compromiso de los involucrados con el medio ambiente y una mayor autonomía de los estudiantes en la toma de decisiones y la búsqueda de soluciones a los problemas detectados. Expresaron, de igual forma, interés en la creación de un club basado en la educación ambiental y la reutilización de las aguas para promover la sostenibilidad de los recursos hídricos en el entorno escolar.

Palabras-clave:Educación ambiental. Sostenibilidad. Agua.

\section{Introdução}

Os problemas ambientais decorrentes da ação antrópica, têm comprometido a qualidade de vida e a saúde de várias pessoas. A apropriação da ciência e da técnica pelo capitalismo, objetivando facilitar e agilizar o acúmulo do capital, repercutiu seriamente na degradação do meio ambiente, destruindo a vida de várias espécies e colocando em risco a nossa própria existência. Pautada numa ideia falsa de progresso da civilização moderna, a racionalidade econômica gerou todo esse processo de destruição ecológica e degradação ambiental que se manifesta como sintoma de uma crise de civilização (LEFF, 2018).

$\mathrm{Na}$ década de 60 do século passado a crise ambiental se tornou evidente. O debate sobre a problemática ambiental se concretizou, favorecendo uma ampla discussão teórica e política sobre a valorização da natureza, onde foi sendo configurado um conceito de ambiente como uma nova visão de desenvolvimento humano, como um saber reintegrador da diversidade, pautado em novos valores éticos e em prol da construção de uma racionalidade ambiental que requer um novo saber, o saber ambiental. Este, "leva a

ParaOnde!?, Porto Alegre, v.12 n.2, p.124-134, 2019.http://seer.ufrgs.br/paraonde Edição Especial - III Colóquio de Pesquisadores em Geografia Física Ensino de Geografia 
um diálogo e amálgama de saberes, desde os níveis mais altos de abstração conceitual até os níveis do saber prático e cotidiano onde se expressam suas estratégias e práticas." (LEFF, 2018, p.153). Assim, ele valoriza além do conhecimento cientifico os saberes sociais. Sobre o saber ambiental Leff (2018, p. 152) ainda observa que,

O saber ambiental é pois gerado num processo de conscientização, de produção teórica e de pesquisa científica. O processo educativo permite repensar e reelaborar o saber, na medida em que se transformam as práticas pedagógicas correntes de transmissão e assimilação do saber preestabelecido e fixado em conteúdos curriculares e na prática de ensino.

Desta forma, fica evidente a importância da educação na formação de uma sociedade mais consciente de seu papel nas relações estabelecidas entre ela e o meio ambiente. Desde a formação do professor-pesquisador que planeja e dirige sua prática pedagógica pautada na interdisciplinaridade, no diálogo de saberes e na ação reflexiva até a formação de um aluno também reflexivo: "um sujeito que se re-identifica e contraidentifica dentro das estruturas que o definem e o condicionam, de onde reinventa suas próprias identidades em processos de ressignificação e de emancipação." (LEFF, 2016, p.399)

Pensar na formação desse sujeito no âmbito formal é pensar na educação ambiental nas escolas. De acordo com Coimbra (2005) e Carneiro (2007) a Primeira Conferência sobre Meio Ambiente Humano e Desenvolvimento, realizada em 1972, em Estocolmo na Suécia, foi o marco inicial da preocupação com o meio ambiente. Nela, foi exposta pela primeira vez a necessidade da Educação Ambiental (EA), "como estratégica e prioritária na formação de sujeitos conscientes e preparados frente as questões ambientais" (CARNEIRO, 2007, p. 98). Assim, a escola assume a sua responsabilidade na formação de pessoas mais comprometidas e integradas com o meio ambiente. Seja ele, o do espaço físico da unidade de ensino, seja o que extrapola os muros da escola, que na maioria das vezes é a cidade. Palco principal das relações estabelecidas pela sociedade, o local de reprodução intensa do capital e da degradação ambiental proveniente dessa reprodução.

Segundo Mendonça (2004) as grandes metrópoles do Brasil estão vivendo uma crise ambiental severa vinculada a vários problemas crescentes e prejudiciais que degradam a paisagem. Dentre eles, a redução das áreas verdes, por ocasião da impermeabilização dos solos e consequente redução do nível de infiltração da água da chuva no mesmo, o que ocasiona sérios problemas relacionados a enchentes e alagamentos em épocas de chuvas fortes, bem com a contaminação da maioria dos mananciais de água e dos rios nas cidades, e consequentemente os riscos que a população fica exposta principalmente em áreas onde ocorrem enchentes e alagamentos.

Outro problema sério das áreas urbanas é a falta de tratamento dos efluentes, que muitas vezes são jogados diretamente na rede pluvial ou nos rios. Consequentemente ocorre a deterioração da qualidade da água e da saúde das pessoas que podem utilizá-la para vários fins, como o lazer por exemplo. Segundo Tucci (2008) a cobertura de coleta e tratamento de esgoto no Brasil é considerada baixa, e tendo em vista que as cidades continuam a crescer pode-se afirmar que o desenvolvimento urbano tem repercutido num ciclo de contaminação gerado pelos efluentes da população urbana.

Tendo em vista que as áreas urbanas demandam muita água para a produção do

ParaOnde!?, Porto Alegre, v.12 n.2, p.124-134, 2019.http://seer.ufrgs.br/paraonde Edição Especial - III Colóquio de Pesquisadores em Geografia Física Ensino de Geografia 
espaço urbano e para prover as necessidades de seus habitantes, e que a cada dia que passa é mais caro satisfazer essa demanda (RIBEIRO, 2008), fica evidente a necessidade de repensar as relações e posturas da sociedade com relação a esse bem natural que é fundamental para a vida humana.

De acordo com Bacci e Pataca (2008) educar para a água é imprescindível e essa abordagem deve acontecer interdisciplinarmente, pois enquanto tema de geociências, disseminado em vária disciplinas, deve ser tratado visando superar a atual fragmentação do conhecimento, e a separação entre o homem e a natureza. Deve focar na "ética e na formação de cidadãos conscientes do lugar que ocupa no mundo, num mundo real, dinâmico, que parte do local e se relaciona com o global, onde todas as coisas podem tomar parte de um processo maior, de um sistema integrado" (BACCl e PATACA, 2008, p.217).

Desta forma, repensar nossas práticas e a nossa relação com o meio ambiente é mais que fundamental. É indispensável a colaboração dos dirigentes e da sociedade na busca de soluções para o problema exposto. É necessário reduzir o consumo, pensar e desenvolver práticas sustentáveis como o reuso das águas. E a escola, como espaço formal da educação e aprendizagem deve assumir seu papel, estimulando a execução de atividades e projetos interdisciplinares voltados para esse fim. Assim, propiciará a formação de um cidadão mais crítico, consciente e preocupado com o meio em que vive. Criará sujeitos capazes de repensar uma nova sociedade, mais harmônica e comprometida com a sustentabilidade. O sujeito ecológico, que possua um modo cuidadoso de se relacionar com outros seres humanos, não humanos e com o meio ambiente como um todo, pois está relacionado a um modo específico de ser no mundo. Um ser humano imbuído de ideais que inspirem atitudes ecologicamente orientadas (CARVALHO, 2013).

Na perspectiva de formar um cidadão mais crítico, consciente e preocupado com o meio em que vive, torna-se necessário repensar a forma de ensinar Geografia. Assim, a partir do pressuposto que o ensino se torna mais significativo e atrativo para o aluno quando este aborda a sua realidade, ou seja, as condições de seu cotidiano, torna-se necessário extrapolar os muros da escola, promover estudo do meio onde a realidade de dentro e de fora da escola sejam analisadas e possam propiciar a construção de conceitos pelos próprios alunos. "Na verdade, a Geografia deveria ter como laboratório, o próprio ambiente onde vivemos. A Geografia deveria ser ensinada sem programação fixa, sem livros didáticos e nunca fechada em quatro paredes." (PASSINI, 2001, P.174)

Desta forma, o entorno onde a escola está inserida deve ser encarado como um laboratório à céu aberto, onde as oportunidades de aprendizagem se ampliam consideravelmente. Nele, o aluno entende o local, pode exercitar a observação sobre o espaço vivido, analisando-o de forma crítica e podendo ampliar sua noção de mundo fazendo relações com o global. "Estudar a realidade circundante é buscar o entendimento do que está acontecendo, seja no lugar, seja no mundo." (CALLAI, 2010, p. 25)

É necessário que o aluno consiga compreender o mundo e isso pode ser feito através da leitura do lugar, do espaço vivido pelos alunos cotidianamente. Nessa perspectiva, "Lugar e cotidiano são abordados no contexto escolar como oportunidade de desenvolver habilidades e competências que contribuem para a formação cidadã e para a construção de conceitos constitutivos da especificidade do conhecimento geográfico e para o estabelecimento das bases da aprendizagem da geografia na escola básica."

ParaOnde!?, Porto Alegre, v.12 n.2, p.124-134, 2019.http://seer.ufrgs.br/paraonde

Edição Especial - III Colóquio de Pesquisadores em Geografia Física Ensino de Geografia 
(CALLAI, 2010, p. 25)

Planejar ações dentro e fora do ambiente escolar são atitudes fundamentais para que 0 aluno possa construir conceitos de forma crítica e autônoma. Estas devem estar presentes no planejamento e nas ações do professor, mas para que isso ocorra o mesmo deve planejar seu trabalho focado no que é mais importante ensinar em geografia, criando assim condições para que as ações voltadas para o estudo do meio possam ser realizadas. Desta forma será dada a oportunidade necessária para que o aluno “(...) possa fazer a sua leitura de mundo, que poderá ser feita a partir do conhecimento geográfico relacionado com a sua realidade." (CASTELLAR, 2015, p.57)

$\mathrm{Na}$ perspectiva de educar para a água, através da sensibilização da comunidade escolar para o uso sustentável da mesma, a pesquisa - ação foi desenvolvida no Colégio Estadual Professor Gonçalo Rollemberg Leite - CEPGRL, localizado no bairro Gragerú, no município de Aracaju -SE.

A unidade de ensino funciona nos turnos matutino e vespertino, com as seguintes modalidades: fundamental maior, ensino médio regular, ensino médio inovador e ensino médio integral. Atende um total de 855 alunos oriundos de vários bairros da cidade, de alguns municípios vizinhos e também do interior.

Possui 18 salas de aula, sala dos professores, sala de vídeo, laboratório de informática, biblioteca, auditório, sala de dança, quadra de esportes, refeitório, cozinha, cantina, comitê pedagógico, secretaria, coordenação pedagógica, diretoria, almoxarifado, banheiros masculino e feminino para alunos, professores e funcionários. Somando um total de $345.809 \mathrm{~m} 2$ de área construída. A escola também possui área verde, onde são encontradas árvores e plantas, como também solo descoberto.

A escola apresenta alguns problemas ligados a relação da comunidade com o meio ambiente. É uma constante verificar que os alunos desperdiçam água potável ao deixar torneiras e bebedouros abertos. O que acarreta além da perda desse bem natural, escasso em muitas partes do planeta, o aumento das contas de água da unidade de ensino.

A demanda e o consumo de água potável na escola é grande, pois a mesma é utilizada para todos os fins, desde o preparo da merenda escolar até a limpeza do chão e rega de plantas. Além disso todo esgoto gerado é eliminado na rede que por sua vez despeja os resíduos em um dos vários canais que cortam os bairros Gragerú e Jardins, que por fim despeja todo o esgoto no Parque ecológico do Tramandaí, gerando um impacto ambiental significativo no manguezal presente na área.

Assim, no bairro onde a escola está inserida é marcante a presença dos canais, que correm a céu aberto, e que algumas vezes chegam a transbordar nos dias de chuvas fortes. Nesses episódios as águas das chuvas se misturam aos dejetos do esgoto que alagam algumas ruas e avenidas do bairro, provocando a dificuldade de acesso a própria escola.

Desta forma, essa pesquisa-ação teve como objetivo principal desenvolver ações pedagógicas focadas na promoção da educação ambiental e no uso sustentável da água. Como objetivos específicos: Verificar a postura da comunidade escolar em sua relação com o meio ambiente e mais especificamente com relação a utilização da água; Sensibilizar os alunos quanto ao uso racional da água; Desenvolver uma ação interdisciplinar, integrando alunos e professores em prol da sustentabilidade dos recursos

ParaOnde!?, Porto Alegre, v.12 n.2, p.124-134, 2019.http://seer.ufrgs.br/paraonde Edição Especial - III Colóquio de Pesquisadores em Geografia Física Ensino de Geografia 
hídricos; Divulgar as ações junto à comunidade escolar como forma de envolver mais pessoas no processo de sensibilização para a sustentabilidade dos recursos hídricos.

Que essa iniciativa tenha sido uma sementinha plantada no chão fecundo de uma escola sonhada e desejada sustentável.

\section{Desenvolvimento}

A ação Sensibilizar para a água: educação ambiental no Colégio Estadual Professor Gonçalo Rollemberg Leite, realizada nos meses de maio e junho do corrente ano, envolveu alunos e professores do 1ำ ano do Ensino Médio Integral da unidade de ensino. A mesma, desenvolvida dentro da disciplina eletiva intitulada "A água nossa de cada dia" foi executada de acordo com as seguintes etapas ou procedimentos:

Etapa 1 - Divulgação da ação na escola.

Etapa 2 - Atividade na escola com rodas de conversa, produção de cartazes e exibição de vídeo educativo.

Etapa 3 - Atividade no II Simpósio da Bacia Hidrográfica do Rio São Francisco.

Etapa 4 - Trabalho de campo no entorno da escola e atividade exploratória no ambiente escolar.

Etapa 5 - Discussão e reflexões sobre as ações realizadas com roda de conversa, produção de cartazes, poemas, painel, paródia e apresentação teatral. escolar.

Etapa 6 - Culminância com apresentação dos resultados junto a comunidade

A divulgação da ação pedagógica ocorreu através de cartazes que foram fixados no corredor da escola. A mesma também foi apresentada aos alunos e professores na Feira das Disciplinas Eletivas do Ensino Médio Integral realizada no mês de maio no auditório da unidade de ensino.

$\mathrm{Na}$ execução das atividades da etapa 2 , foi realizada uma roda de conversa, onde os alunos foram instigados, através de palavras- geradoras, a demonstrar o conhecimento que possuem e expressar suas opiniões relacionadas ao meio ambiente, natureza, água, escola e comunidade. Os mesmos participaram ativamente da roda de conversa e demonstraram que conheciam as palavras geradoras trabalhadas, inclusive, alguns explicaram as relações que existem entre elas, colaborando bastante com a discussão.

Em seguida os mesmos registraram essas informações em cartazes, através da produção escrita e de desenhos, que foram fixados na sala de aula e analisados por todos os alunos (Figura 1).

ParaOnde!?, Porto Alegre, v.12 n.2, p.124-134, 2019.http://seer.ufrgs.br/paraonde Edição Especial - III Colóquio de Pesquisadores em Geografia Física Ensino de Geografia 


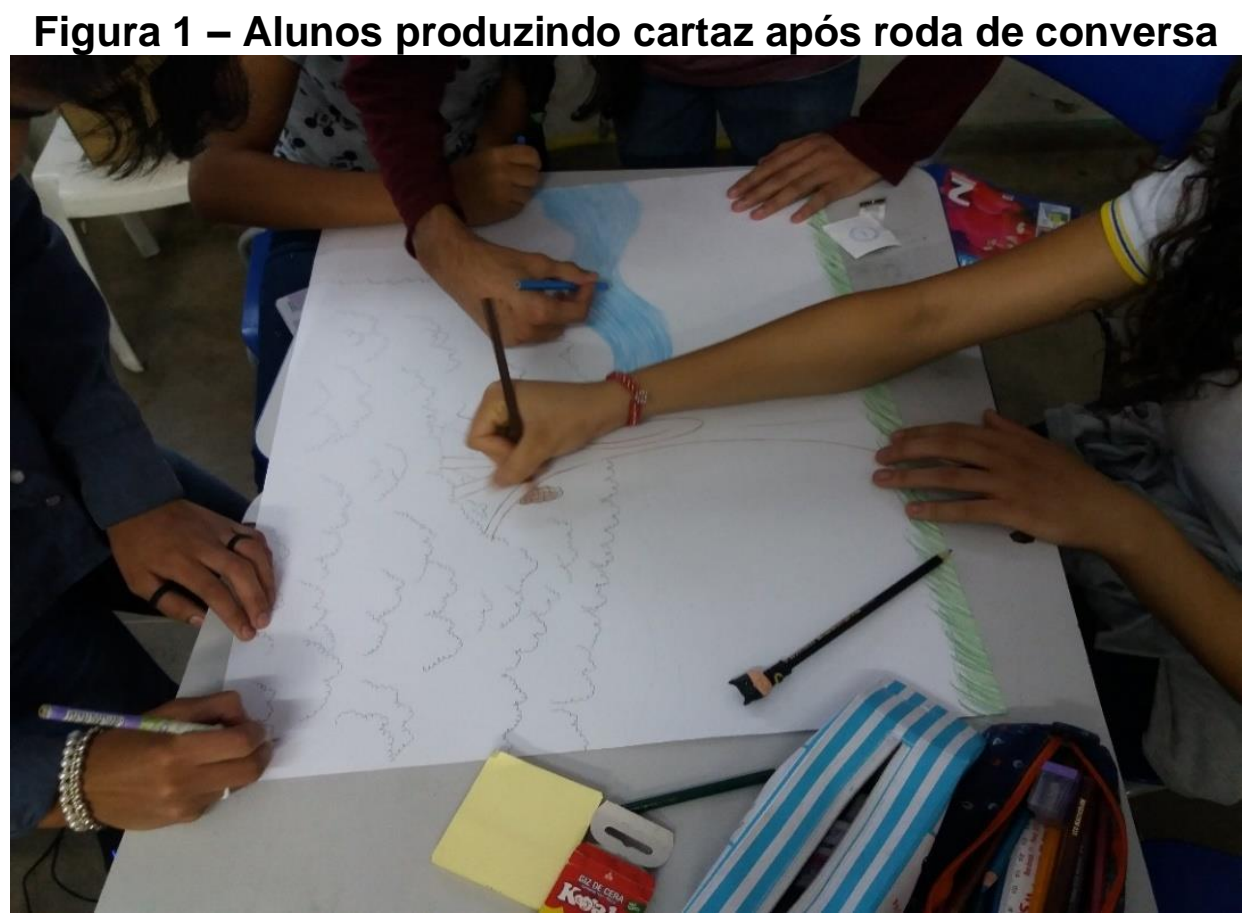

Fonte: Cunha, 2018.

Nessa segunda parte da atividade do dia, confecção de cartazes, todos os alunos foram participativos. Entre as colocações que foram feitas e os cartazes que foram confeccionados pode-se verificar que alguns dos alunos não se percebem natureza e que alguns associam o meio ambiente aos elementos naturais da paisagem. Somente um aluno falou do homem enquanto natureza e esse mesmo aluno fez várias colocações onde os elementos artificias da paisagem foram considerados por ele como meio ambiente. Esse aluno falou ainda sobre a importância da água para a existência da vida no planeta. Não só para a vida humana mas para todas as espécies.

Em seguida foi exibido um vídeo sobre o ciclo hidrológico disponível no site da Agência Nacional de Águas (ANA), que foi seguido por uma discussão a respeito das relações que são estabelecidas entre a sociedade e meio ambiente, assim como a interferência humana na realização desse ciclo. Nesse momento, os alunos fizeram várias colocações sobre as interferências que o homem tem provocado nesse ciclo natural, como por exemplo a impermeabilização dos solos que impedem a infiltração das águas, aumentam escoamento superficial e provocam as enchentes e alagamentos nas épocas das chuvas. Inclusive, alguns alunos citaram os alagamentos que ocorrem no bairro onde moram, como também os que ocorrem no bairro onde a escola está localizada.

$\mathrm{Na}$ execução da etapa 3, realizada no dia 04 de junho do corrente ano, os professores de geografia, sociologia, biologia, filosofia, matemática e história acompanharam os alunos a exposição "Eu amo o Velho Chico" no II Simpósio da Bacia Hidrográfica do Rio São Francisco realizado na Universidade Federal de Sergipe, no Campus de São Cristóvão. Os alunos foram orientados a observar, questionar e anotar informações que achassem relevantes a realização do nosso trabalho. Assim, perguntaram e tomaram nota sobre a localização da bacia do rio São Francisco, captação de água para o abastecimento urbano e irrigação, geração de energia elétrica, impactos ambientais por conta da ação antrópica, entre outros.

Desta forma puderam ampliar seus conhecimentos com relação ao conceito de

ParaOnde!?, Porto Alegre, v.12 n.2, p.124-134, 2019.http://seer.ufrgs.br/paraonde Edição Especial - III Colóquio de Pesquisadores em Geografia Física Ensino de Geografia 
bacia e de região hidrográfica, também tiveram condições de perceber a importância do rio São Francisco para a população ribeirinha e para as demais populações de vários estados nordestinos que necessitam de suas águas para sobreviver, seja de forma direta, como o abastecimento para o consumo ou indireta como a energia. Alguns alunos lembraram que nós, habitantes de Aracaju, dependemos fortemente do rio no que tange o abastecimento urbano e fornecimento de energia elétrica que é produzida em Xingó. Assim, eles puderam perceber que nossas relações com o meio ambiente vão além do local e do cotidiano, que tudo está interligado e que nossas ações e relações de interdependência com os outros elementos que compõem o meio ambiente atingem escalas regionais e globais.

A execução da etapa 4, trabalho de campo pelo bairro Gragerú, objetivou instigar o olhar do aluno as problemáticas existentes no bairro, em particular os canais, onde o esgoto corre a céu aberto, sem nenhum tratamento, e cujas águas poluídas são jogadas no Manguezal do Tramandaí (Figura 2). Os alunos foram estimulados a observar e refletir sobre o fato desses problemas ambientais existirem no bairro, bem como pensar em soluções que possam repercutir na minimização desses impactos ambientais. Foram orientados pelas professoras que realizaram a atividade a anotar informações, observações e a fazer registro fotográfico do que achassem necessário. Participaram dessa atividade 20 alunos e as professoras de geografia e biologia.

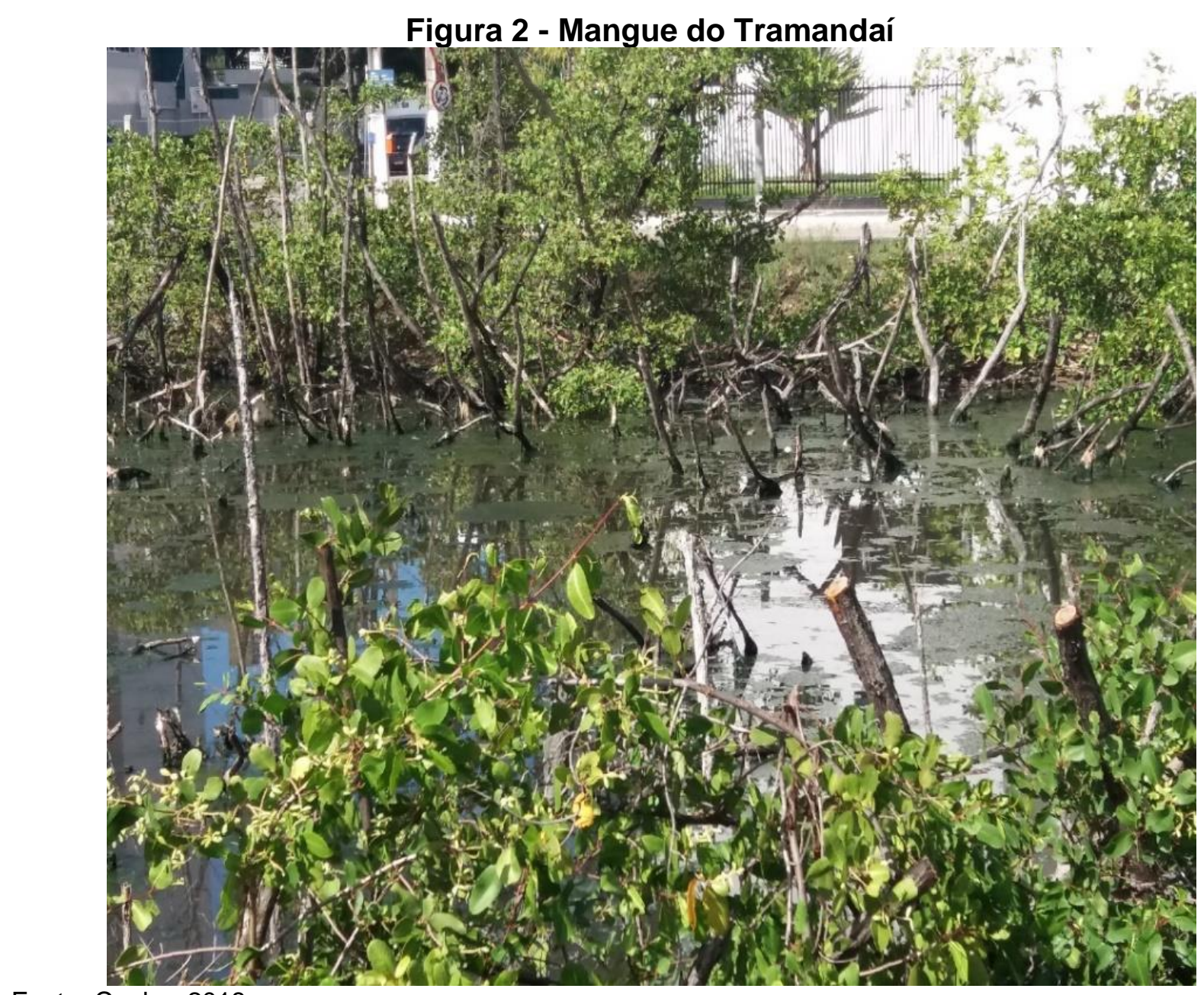

Fonte: Cunha, 2018.

ParaOnde!?, Porto Alegre, v.12 n.2, p.124-134, 2019.http://seer.ufrgs.br/paraonde Edição Especial - III Colóquio de Pesquisadores em Geografia Física Ensino de Geografia 
Nas paradas os alunos comentaram sobre o mau cheiro proveniente dos canais, já que estes recebem todos os efluentes oriundos das residências e comércios existentes no bairro. Também falaram sobre os transbordamentos provocados pelas chuvas fortes quando estas coincidem com as marés mais altas e dificultam o acesso de alguns alunos à escola. Lembraram que ficam expostos a doenças e acidentes quando isso ocorre. As professoras falaram sobre as águas negras, as águas cinzas e de como a quantidade de efluentes poderia ser diminuída se houvesse o reuso.

No manguezal do Tramandaí os alunos observaram que o mesmo está morrendo por conta da grande quantidade de esgoto jogado no local, mas que mesmo assim a vida resiste, pois podem ser encontradas aves, aratus, borboletas, besouros e vários outros animais que ali vivem.

De volta à escola, foi realizada uma roda de conversa onde os alunos foram provocados a refletir a respeito da relação da sociedade com o meio ambiente fora do espaço escolar e em seguida dentro da unidade de ensino. Nesse momento foram abordados problemas ambientais percebidos por eles quando visitaram a exposição "Eu amo o Velho Chico", como a diminuição da vazão do rio, e problemas verificados no entorno da escola, como a falta de tratamento dos efluentes e degradação do manguezal do Tramandaí.

Os alunos foram então questionados sobre a realidade da escola. As professoras perguntaram se a escola apresentava problemas ambientais por conta da falta de cuidado da comunidade para com a mesma. Todos responderam que sim e a maioria citou como exemplo os resíduos sólidos jogados fora do lugar adequado, o desperdício de água nos bebedouros e na caixa d'água que quando enche sempre transborda. Em seguida foram orientados a fazer uma atividade de exploração e registrar com as câmeras dos aparelhos celulares os problemas ambientais encontrados. Essa atividade durou 30 minutos. Nela, os alunos identificaram e registraram através de fotografias, os problemas já citados por eles antes da atividade, bem como torneiras quebradas ou com defeito, canos quebrados e descargas sanitárias com vazamento, o que provoca a perda do recurso hídrico.

Ao retornarem da atividade no ambiente escolar, os alunos passaram as imagens para o notebook e estas foram projetadas na lousa, possibilitando que todos pudessem observá-las e refletir sobre cada uma delas. Assim, eles colocaram que falta assistência e manutenção por parte da gestão mas que falta acima de tudo compromisso, responsabilidade e vontade de querer cuidar por parte dos alunos. Decidiram conversar com a gestão sobre a situação de destruição do patrimônio escolar e consequente desperdício de água, como também tentar sensibilizar os colegas com relação a preservação do mesmo.

Na concretização da etapa 5 do projeto, foi realizado um encontro onde os alunos expuseram suas opiniões com relação as atividades desenvolvidas e refletiram sobre 0 impacto das mesmas para a sua formação enquanto sujeito ecológico. Foram feitas colocações sobre a mudança de postura com relação ao uso da água, como por exemplo 0 ato de usar garrafas e canecas ao ir ao bebedouro, o que evita o desperdício se comparado ao ato de beber diretamente no jato de água que sai da torneirinha. Outros falaram sobre a importância de continuar cuidando do ambiente escolar e de tentar sensibilizar outras pessoas quanto ao uso sustentável dos recursos hídricos. Desta forma, o grupo pode fazer uma síntese das ações desenvolvidas e em seguida, divididos em grupo ou individualmente, produziram cartazes, poema, versos, apresentação teatral,

ParaOnde!?, Porto Alegre, v.12 n.2, p.124-134, 2019.http://seer.ufrgs.br/paraonde Edição Especial - III Colóquio de Pesquisadores em Geografia Física Ensino de Geografia 
paródia e painel que foram utilizados na culminância do trabalho realizada no auditório e posteriormente expostos no corredor central da escola.

A ação pedagógica aqui apresentada, despertou nos alunos o interesse pelas atividades com foco na água desde o início. Tendo em vista que a disciplina eletiva na qual a pesquisa- ação está inserida foi a mais procurada pelos alunos na hora de efetivar a matrícula. Rapidamente as vagas se esgotaram e houve pedido, junto à coordenação pedagógica da escola, para ampliar o número de vagas da mesma. No entanto o pedido não foi atendido, visto que a coordenação preferiu distribuir de forma mais equilibrada o número de alunos por disciplina.

Desta forma as atividades foram iniciadas com um total de vinte alunos interessados pela temática proposta e foi finalizada com o mesmo número, não ocorrendo nenhuma desistência. Algo que é muito bom tendo em vista que não há reprovação nas disciplinas eletivas. O aluno faz pelo fato de realmente gostar da temática proposta e da metodologia utilizada no desenvolvimento da mesma.

Todos os alunos do Ensino Médio Integral participaram da culminância do projeto, onde puderam verificar os resultados do trabalho que foram apresentados pelos próprios alunos que estiveram envolvidos nas atividades. Posteriormente o material produzido foi exposto no corredor central da escola. Assim, foi criado um painel permanente cujos alunos intitularam "Saber Cuidar."

\section{Considerações finais}

Acreditamos que a realização das atividades pedagógicas de educação ambiental desenvolvidas no Colégio Estadual Professor Gonçalo Rollemberg Leite tenham sensibilizado alunos e professores envolvidos na realização das mesmas. Em muitos momentos foi notado o dever de responsabilidade para com o meio ambiente e a autonomia de vários alunos que participaram ativamente do projeto e chegaram a mencionar a formação de um grupo de protagonismo em Educação Ambiental. Mas, tendo em vista que o processo de sensibilização é lento, pois depende inteiramente do fato do outro querer mudar, sabemos que o trabalho está só começando.

Desta forma, pensamos que a execução deste trabalho tenha iniciado um processo de formação de sujeitos ecológicos, ou seja, comprometidos com o meio ambiente e, sendo assim, com a água e a vida. Ações futuras relacionadas a formação de clube de protagonismo em educação ambiental, ao reuso das águas e a sustentabilidade consistem na nossa maior perspectiva com relação a continuidade desse trabalho.

\section{REFERÊNCIAS}

BACCI, Denise de La Corte; PATACA, Ermelinda Moutinho. Educação para a água. Estudos avançados, São Paulo, v. 22, n. 63, p. 211-226, Janeiro 2008.

CALLAI, Helena Copetti. Escola, cotidiano e lugar. Ensino fundamental, 2010.

CARNEIRO, Sonia Maria Marchiorato. Ética e Educação: a questão ambiental. Revista de Educação PUC-Campinas, Campinas, n. 22, p.97-107, junho 2007.

ParaOnde!?, Porto Alegre, v.12 n.2, p.124-134, 2019.http://seer.ufrgs.br/paraonde Edição Especial - III Colóquio de Pesquisadores em Geografia Física Ensino de Geografia 
CARVALHO, Isabel Cristina de Moura. O Sujeito ecológico: a formação de novas identidades na escola. In: Pernambuco, Marta; Paiva, Irene. (Org.). Práticas coletivas na escola. 1 ed. Campinas: Mercado das Letras, 2013, v. 1, p.115-124.

CASTELLAR, Sonia Maria Vanzella. A formação de professores e o ensino de Geografia. Terra Livre, São Paulo. v. 1, n. 14, p. 51-59, 2015.

COIMBRA, Audrey de Souza. Interdisciplinaridade e Educação Ambiental: Integrando seus Princípios Necessários. Revista Eletrônica do Mestrado em Educação Ambiental. Rio Grande do Sul, v. 14, p. 115-121, Janeiro a Junho 2005.

LEFF, Enrique. Saber Ambiental: sustentabilidade, racionalidade, complexidade, poder. Tradução de Lúcia Mathilde Endlich Orth. 11aㅡ ed. Petrópolis, RJ. Vozes, 2018. 496 p.

LEFF, Enrique. A Aposta pela Vida: imaginação Sociológica e Imaginários Sociais nos Territórios Ambientais. RJ, Vozes, 2016. 512 p.

MENDONÇA, Francisco. Impactos socioambientais urbanos. Curitiba: Ed. UFPR, $2004.328 \mathrm{p}$.

PASSINI, Elza Yasuko. Geografia: ver, tocar, sentir. Boletim de Geografia. Maringá, v. 19, n. 1, p. 173-178, 2001.

RIBEIRO, Wagner Costa. Geografia política da água. São Paulo: Annablume, 2008. 162 p.

TUCCI, Carlos E. M. Águas Urbanas. Estudos Avançados. São Paulo. v. 22, n. 63, p. $97-$ 112. Janeiro 2008. 